Article

\title{
Achieving Secondary Dispersion of Modified Nanoparticles by Hot-Stretching to Enhance Dielectric and Mechanical Properties of Polyarylene Ether Nitrile Composites
}

\author{
Yong You, Ling Tu, Yajie Wang, Lifen Tong, Renbo Wei * and Xiaobo Liu * \\ Research Branch of Advanced Functional Materials, School of Materials and Energy, University of Electronic \\ Science and Technology of China, Chengdu 610054, China \\ * Correspondence: weirb10@uestc.edu.cn (R.W.); liuxb@uestc.edu.cn (X.L.); Tel.: +86-028-8320-7326 (X.L.)
}

Received: 5 June 2019; Accepted: 10 July 2019; Published: 12 July 2019

\begin{abstract}
Enhanced dielectric and mechanical properties of polyarylene ether nitrile (PEN) are obtained through secondary dispersion of polyaniline functionalized barium titanate (PANI- $f$-BT) by hot-stretching. PANI- $f$-BT nanoparticles with different PANI content are successfully prepared via in-situ aniline polymerization technology. The transmission electron microscopy (TEM), fourier transform infrared spectroscopy (FTIR), X-ray photoelectron spectroscopic instrument (XPS) and Thermogravimetric analysis (TGA) results confirm that the PANI layers uniformly enclose on the surface of $\mathrm{BaTiO}_{3}$ nanoparticles. These nanoparticles are used as functional fillers to compound with PEN (PEN/PANI- $f$-BT) for studying its effect on the mechanical and dielectric performance of the obtained composites. In addition, the nanocomposites are uniaxial hot-stretched by $50 \%$ and $100 \%$ at $280{ }^{\circ} \mathrm{C}$ to obtain the oriented nanocomposite films. The results exhibit that the PANI- $f$-BT nanoparticles present good compatibility and dispersion in the PEN matrix, and the hot-stretching endows the second dispersion of PANI-f-BT in PEN resulting in enhanced mechanical properties, crystallinity and permittivity-temperature stability of the nanocomposites. The excellent performances of the nanocomposites indicate that a new approach for preparing high-temperature-resistant dielectric films is provided.
\end{abstract}

Keywords: nanocomposites; surface-functionalization; secondary dispersion; hot-stretching

\section{Introduction}

With the increasing requirements of modern microelectronic components, the miniaturized and flexible dielectric materials are attracting more and more attention for various applications [1,2]. However, up to now, a single component material has been unable to meet these demands. Although the traditional inorganic ceramic dielectrics are widely used owing to their high dielectric constant, their inherent characteristics of heavy weight, difficult processing and brittleness fail to meet the current practical application [3,4]. In comparison, polymeric materials have exhibited the advantages of being lightweight and flexible, but their low dielectric constant also limits their application to a great extent [5-7]. Therefore, combining the two-component materials is an effective way to overcome these limitations [8-10].

In recent years, polymer-based nanocomposites have proved to be an important dielectric material by virtue of the high dielectric permittivity, flexibility and excellent thermal stability for widely using as dielectrics in the electronic system [11-15]. It is mainly because the nanocomposites can absorb the dominants of polymer matrix and inorganic nanofillers. Nevertheless, the prerequisite for the nanocomposites demonstrating excellent properties is to realize good compatibility between nanoparticles and polymer matrix [16,17]. In general, modifying the micro-interface of the nanoparticles 
can greatly improve the compatibility of nanoparticles with matrix, which can also regulate the dielectric permittivity and thermal stability of composites [18-20]. Thus, it is important to design and fabricate surface functionalized nanoparticles on the basis of maintaining the properties of nanoparticles while improving the compatibility. Polyaniline (PANI), as a conducting polymer, has been widely used as the filler to compound with polymer matrix [21] or as the surface agent to modify the nanoparticles [22,23] by virtue of its excellent conductivity after doping.

Although surface-functionalized nanofillers can effectively improve their compatibility with the matrix enhancing the dispersion of nanofillers in the matrix, they will inevitably agglomerate at a high filler level, resulting in reduced mechanical properties and permittivity-temperature stability. Therefore, it is crucial to find a technology that can achieve secondary dispersion of fillers and improve the overall performance of composites [24]. Uniaxial hot-stretching, a method to achieve high orientation of polymer materials under the action of external force, realizes a secondary uniform dispersion of the fillers along the orientation direction. In addition, the hot-stretching technology can effectively promote the regularity of polymer molecular chains and improve their crystallinity [23-28].

In this paper, novel PANI-functionalized-nanoparticles of different polymer content via in-situ polymerization technology are fabricated and characterized in detail. Also, these surface functionalized nanoparticles are used as functional fillers to promote the performances of polyarylene ether nitrile (PEN). In addition, the PEN-based nanocomposites are uniaxial hot-stretched by 50\% and $100 \%$ at $280{ }^{\circ} \mathrm{C}$. The corresponding properties of the oriented nanocomposite films are investigated in detail.

\section{Experimental}

\subsection{Materials}

$\mathrm{BaTiO}_{3}(\sim 60 \mathrm{~nm}$, cubic) was bought from TPL Co., Dallas, Texas, USA. Potassium carbonate $\left(\mathrm{K}_{2} \mathrm{CO}_{3}\right)$, 2, 6-dichlorobenzonitrile (DCBN), biphenol (BP), ammonium persulfate $\left(\left(\mathrm{NH}_{4}\right)_{2} \mathrm{~S}_{2} \mathrm{O}_{8}\right)$, aniline $\left(\mathrm{C}_{6} \mathrm{H}_{7} \mathrm{~N}\right)$, hydrochloric acid and alcohol were supplied by Chengdu KeLong chemicals, Chengdu, China. N-methyl-2-pyrrolodone (NMP) was bought from Chengdu Changzheng chemicals, Chengdu, China.

\subsection{Preparation of PEN}

PEN was prepared by 2,6-dichlorobenzonitrile and biphenol in our laboratory through the previously reported method [28].

\subsection{Preparation of PANI-f-BT Nanoparticles}

The PANI- $f$-BT nanoparticles were fabricated by in-situ aniline polymerization method [29]. The specific steps are shown in Figure 1a. Firstly, $\mathrm{BaTiO}_{3}(\sim 60 \mathrm{~nm}, 1.0 \mathrm{~g})$ was added into $100 \mathrm{~mL}$ deionized water and ultrasonicated for $1 \mathrm{~h}$. Then the dispersion was cooled to $0-5{ }^{\circ} \mathrm{C}$ with an ice bath (step A). At the same time, a certain amount of aniline dissolved in $50 \mathrm{~mL} \mathrm{HCl}(0.1 \mathrm{M})$ was also cooled in another ice bath. Next, the aniline solution was quickly dripped into the $\mathrm{BaTiO}_{3}$ dispersion under nitrogen atmosphere (step B). After stirring for $1 \mathrm{~h}$, pre-cooled ammonium persulfate dissolving in deionized water was added into the mixture of $\mathrm{BaTiO}_{3} /$ aniline for oxidative polymerization for $18 \mathrm{~h}$ (step C and D). Finally, the PANI-f-BT nanoparticle was obtained through filtration and drying (step E). In addition, the preparation diagram of PANI- $f$-BT nanoparticles is shown in Figure $1 b$. In this system, the molar ratio of ammonium persulfate to aniline is controlled to be 1.2:1, and the amounts of aniline are $0.1,0.2$ and $0.3 \mathrm{~mL}$ for PANI- $f$-BT-a, PANI- $f$-BT-b and PANI- $f$-BT-c, respectively. 
(a)

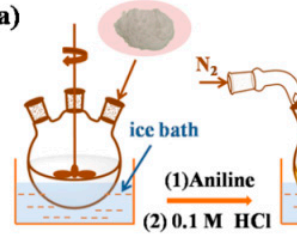

(A)

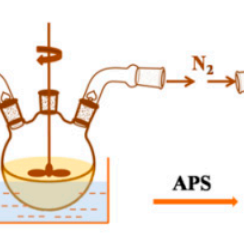

(B)

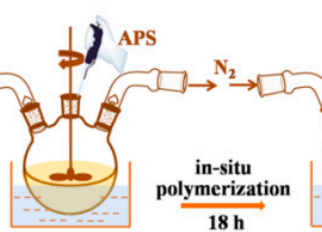

(C)

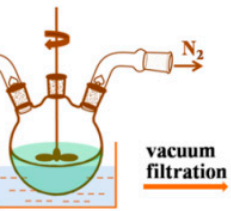

(D)

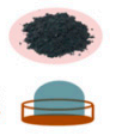

(E)

(b)
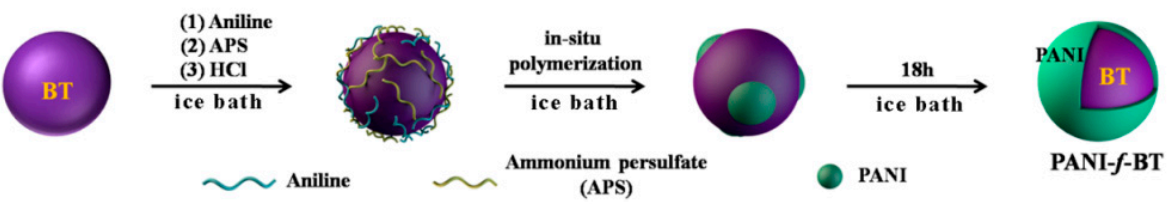

Figure 1. Experimental steps (a) and schematic diagram (b) of the polyaniline functionalized barium titanate (PANI- $f$-BT) nanoparticles.

\subsection{Preparation of Nanocomposites}

PEN-based nanocomposite films with $40 \mathrm{wt} \%$ pure BT and PANI- $f$-BT nanoparticles were prepared by solution casting method [30], which were named PEN/BT, PEN/PANI- $f$-BT-a, PEN/PANI- $f$-BT-b, PEN/PANI- $f$-BT-c, respectively.

\subsection{Preparation of Oriented Nanocomposites by Hot-Stretching}

The orientation process of nanocomposite film was carried out in a $280{ }^{\circ} \mathrm{C}$ oven by uniaxial hot-stretching method according to the previously reported paper [25]. All the nanocomposite films were stretched by $50 \%$ and $100 \%$, respectively. The detailed steps were as follows: first of all, the two ends of the films $(10 \mathrm{~mm} \times 150 \mathrm{~mm})$ were fixed by clamps, where the distance was controlled to be $100 \mathrm{~mm}$; next, one clamp was suspended at the top of the oven, and the other one was hung with a $200 \mathrm{~g}$ balancing weight. The distance between the bottom of the oven and the balancing weight was adjusted to be $50 \mathrm{~mm}$ and $100 \mathrm{~mm}$, corresponding to the stretching ratios of $50 \%$ and $100 \%$. After the films were stretched to the required length, they were quickly removed and quenched in cold water. For comparison, the un-stretched nanocomposite films were also treated at $280{ }^{\circ} \mathrm{C}$ for the same time.

\subsection{Characterization}

The chemical structure of PANI- $f$-BT nanoparticles was characterized on a fourier transform infrared spectroscopy (FTIR, 8400S, Shimadzu, Japan) in the transmission mode between 4000 and $500 \mathrm{~cm}^{-1}$ by incorporating PANI-f-BT in the KBr. The elemental analysis was tested on an X-ray photoelectron spectroscopic instrument (XPS, ESCA 2000, VG Microtech, UK) using a monochromic $\mathrm{Al} \mathrm{K} \alpha\left(h_{v}=1486.6 \mathrm{eV}\right) \mathrm{X}$-ray source. The micro-structures of PANI-f-BT were carried out on the transmission electron microscopy (TEM, JEM-2100F, JEOL, Japan) at $200 \mathrm{kV}$ by dispersing PANI-f-BT on the copper network. The micro-structures of the PANI-f-BT nanocomposites were also obtained using a scanning electron microscopy (SEM, 6490LV, JSM, Japan) at $20 \mathrm{kV}$ by sputtering gold on the fractured surface of PANI-f-BT. The crystalline structure of PANI-f-BT was characterized by X-ray diffractometer (XRD, RINT2400, Rigaku, Japan) with $\mathrm{Cu} \mathrm{K} \alpha$ radiation. Thermal properties of samples were tested under $\mathrm{N}_{2}$ atmosphere by differential scanning calorimetry (DSC, Q100, TA Instruments, New Castle, USA) from $40{ }^{\circ} \mathrm{C}$ to $380{ }^{\circ} \mathrm{C}$ with a heating rate of $10{ }^{\circ} \mathrm{C} / \mathrm{min}$ and Thermogravimetric analysis (TGA, Q50, TA Instruments, New Castle, USA) from $50{ }^{\circ} \mathrm{C}$ to $800{ }^{\circ} \mathrm{C}$ with a heating rate of $20^{\circ} \mathrm{C} / \mathrm{min}$. The mechanical properties of the compounds were measured by Universal Testing Machine (SANS CMT6104, China) with a stretching speed of $5 \mathrm{~mm} / \mathrm{min}$. All the films were cut into standard strips (10 $\mathrm{mm} \times 150 \mathrm{~mm}$ ), and the reported data is the average value obtained by testing five samples. The Dielectric properties of the polymeric compounds were tested on a precision LCR meter (TH 2819A, Tonghui, China). The films were cut into regular pieces $(10 \mathrm{~mm} \times 10 \mathrm{~mm})$ and both sides were coated with the conductive silver paste to form a plate capacitor. 


\section{Results and Discussion}

\subsection{Microstructure and Morphology of PANI-f-BT}

In this work, enhanced dielectric and mechanical properties of PEN are obtained by hot-stretching. PANI- $f$-BT nanoparticles with different polymer content are fabricated via in-situ aniline polymerization technology by controlling the content of aniline, and then incorporated into PEN matrix by ultrasonication achieving the first dispersion of the fillers in PEN matrix. In addition, the PEN-based nanocomposites are uniaxial hot-stretched by $50 \%$ and $100 \%$ at $280{ }^{\circ} \mathrm{C}$, obtaining the second dispersion of the fillers. Resulting from the excellent compatibility between PANI- $f$-BT and PEN and the second dispersion of PANI- $f$-BT in PEN by hot-stretching, the obtained composites demonstrate enhanced crystallinity, mechanical and dielectric properties.

In order to characterize the microstructure of the functionalized nanoparticles, BT and PANI- $f$-BT are characterized by TEM, as shown in Figure 2a,b. It can be seen from Figure $2 \mathrm{a}$ that BT shows a smooth surface without distinct interface at its periphery. In comparison, Figure $2 \mathrm{~b}$ shows different interfaces at the edges of PANI- $f$-BT. A layer of polymer corona is uniformly coated around the BT, indicating that the surface of BT is wrapped with a compact polyaniline layer [31]. The chemical structure of PANI-f-BT is characterized by FTIR (Figure 2c). It is clear that the strong band at $567 \mathrm{~cm}^{-1}$ spectra of pristine BT and PANI- $f$-BT is corresponding to the vibration of Ti-O [32]. Besides, obvious absorption bands at 1586 and $1497 \mathrm{~cm}^{-1}$ can be found on the FTIR spectrum of PANI- $f$-BT, which belong to the skeleton vibration of benzene rings from polyaniline [33]. Compared to BT, the additional characteristic absorption peaks at 3428 and $1189 \mathrm{~cm}^{-1}$ from the spectrum of PANI- $f$-BT are the absorption peaks of N-H and Ar-N vibration, which proves that polyaniline exists in the PANI- $f$-BT [33].
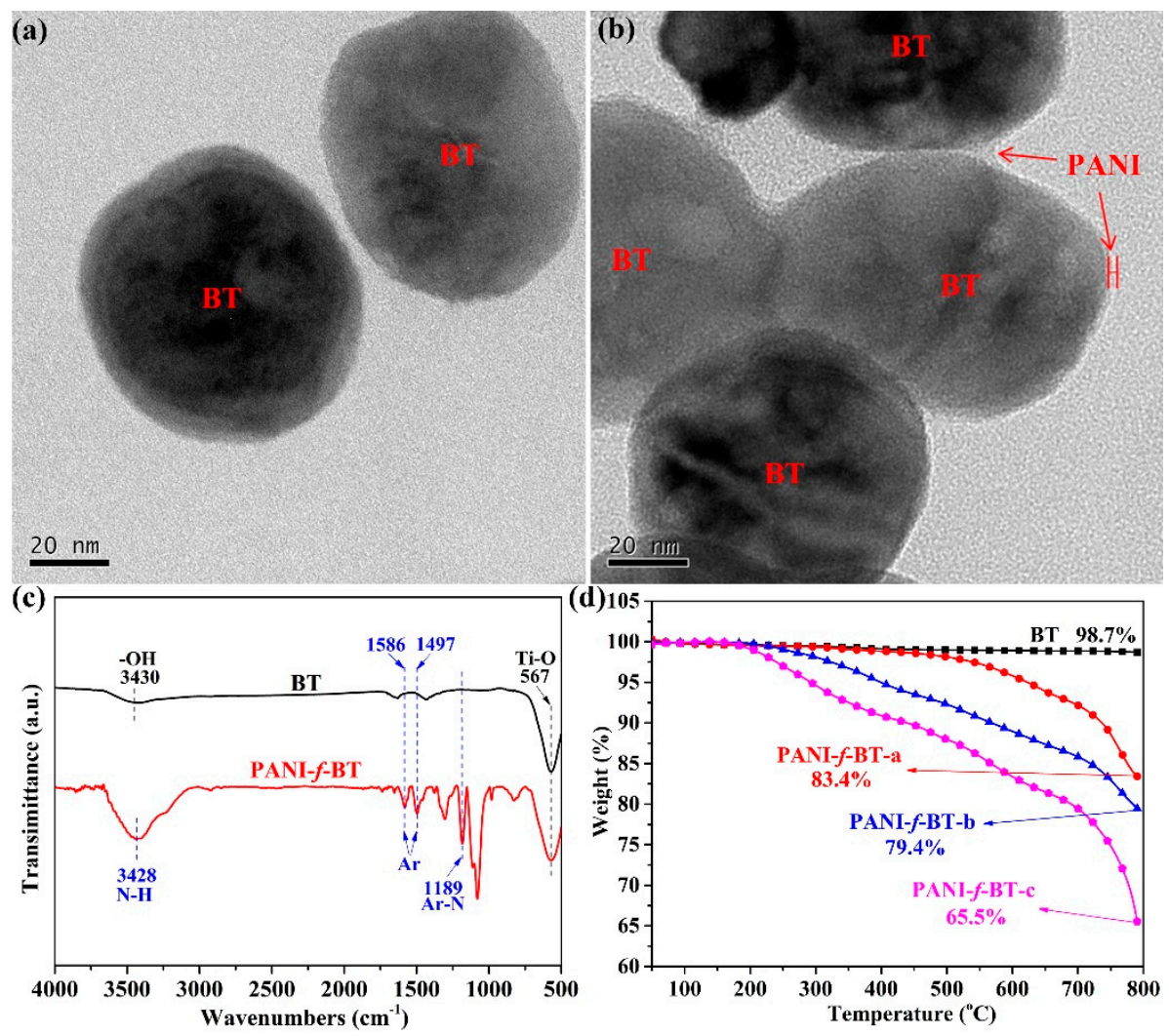

Figure 2. Transmission electron microscopy (TEM) images of (a) barium titanate (BT) and (b) polyaniline functionalized barium titanate (PANI- $f$-BT-b); (c) Fourier transform infrared spectroscopy (FTIR) spectrum of BT and PANI- $f-B T-b ;(d)$ Thermogravimetric analysis (TGA) curves of the nanofillers. 
In addition, the chemical composition of the obtained PANI- $f$-BT is further characterized by XPS measurement (Figure 3). As shown in Figure 3a, it is obvious that the Ba3d, Ba4d, Ba4p, Ti2p and O1s peaks can be observed on the full scanned XPS spectrum of PANI- $f$-BT indicating the existence of BT. In addition, two peaks at $286 \mathrm{eV}$ and $402 \mathrm{eV}$ on the spectrum of PANI- $f$-BT are corresponding to C1s and N1s from polyaniline. Ba3d spectrum of PANI- $f$-BT presents two peaks at 779.6 and $794.9 \mathrm{eV}$ which belong to $\mathrm{Ba}_{3} \mathrm{~d}_{5 / 2}$ and $\mathrm{Ba}_{3} \mathrm{~d}_{3 / 2}$, respectively (Figure $3 \mathrm{~b}$ ) [34]. The Ti2p spectrum of PANI- $f$-BT also shows two peaks at $457.9 \mathrm{eV}\left(\mathrm{Ti}_{2} \mathrm{p}_{3 / 2}\right)$ and $463.9 \mathrm{eV}\left(\mathrm{Ti} 2 \mathrm{p}_{1 / 2}\right)$ (Figure 3c) [32]. What is more, the N1s spectrum of PANI- $f$-BT can be differentiated into three peaks: $398.1 \mathrm{eV}(-\mathrm{N}=), 398.9 \mathrm{eV}(-\mathrm{NH}-)$ and $400.1 \mathrm{eV}\left(\mathrm{N}^{+}\right)$, respectively [35] as shown in Figure 3d.
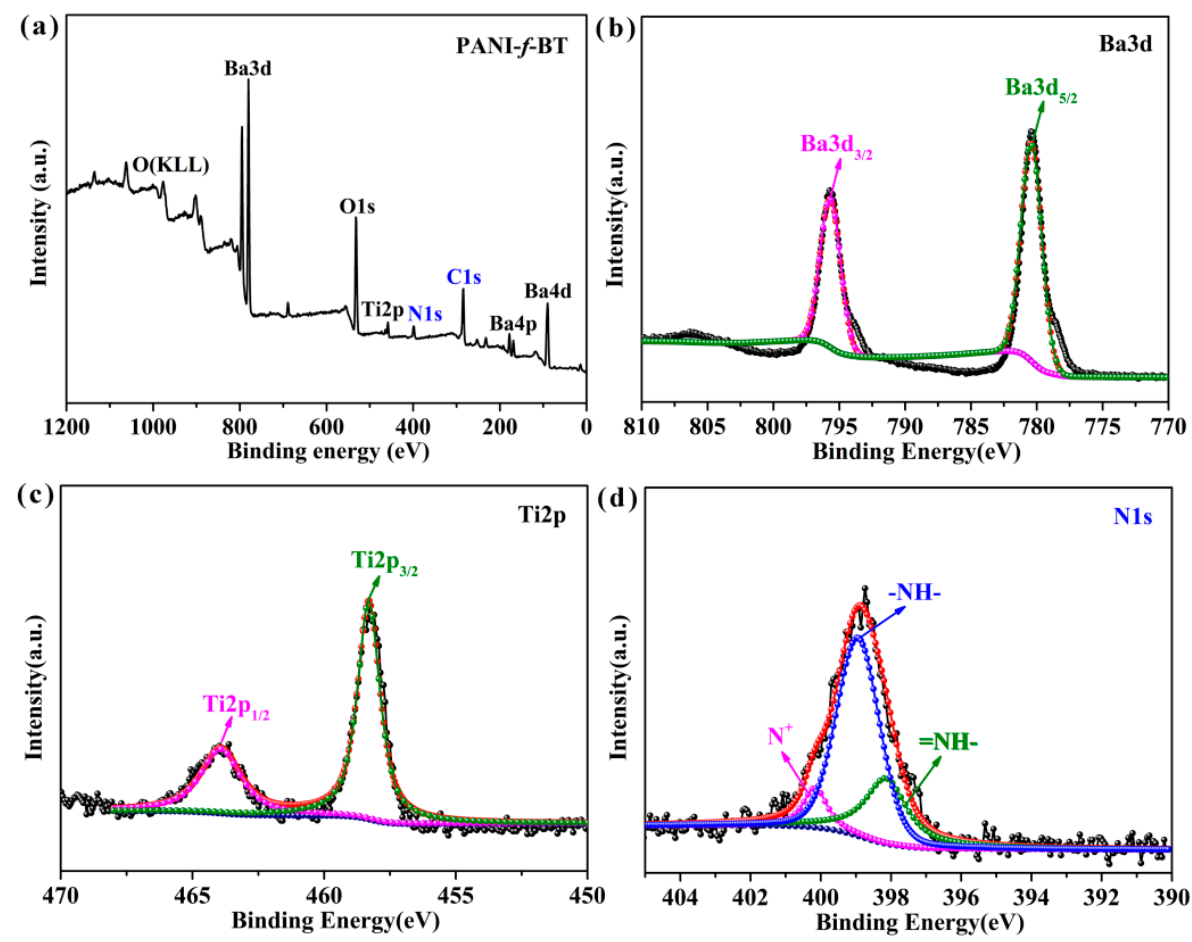

Figure 3. The X-ray photoelectron spectroscopic instrument (XPS) spectrum of PANI-f-BT-b: (a) full scanned spectrum; (b) Ba3d; (c) Ti2p; (d) N1s.

Beside the characterization of PANI- $f$-BT, the contents of polyaniline in PANI- $f$-BT are determined by TGA test. As shown in Figure $2 d$, it is clear that BT nanoparticle does not demonstrate any weight loss, even when heated to $800{ }^{\circ} \mathrm{C}$. In comparison, the residue of PANI- $f$-BT-a, PANI- $f$-BT-b and PANI- $f$-BT-c is $83.4 \%, 79.4 \%$ and $65.5 \%$ at $800{ }^{\circ} \mathrm{C}$, respectively. The decrement of the residue indicates the existence of PANI in PANI- $f$-BT. Simultaneously, the less residue of the PANI- $f$-BT nanoparticles, the more PANI in the PANI- $f$-BT nanoparticles. Therefore, all these results including TEM, FTIR, XPS and TGA suggest that PANI is successfully grown on the surface of BT after the in-situ polymerization procedure.

\subsection{Morphology of PEN/PANI-f-BT Composites}

After the fabrication and characterization of the PANI- $f$-BT nanoparticles, they are introduced into the PEN matrix to prepare the PEN/PANI- $f$-BT composites. The miscibility between PANI- $f$-BT and PEN matrix, which is one of the most important factors affecting the properties of the nanocomposites, is firstly investigated by SEM measurement. Figure 4a shows the microstructures of PEN/BT nanocomposites, which exhibit a poor interfacial adhesion. In addition, a large number of BT nanoparticles are observed at the cross-section of the PEN matrix with serious spherical agglomeration. This phenomenon is mainly due to the high content of BT as well as the poor miscibility between PEN and BT [36]. Contrarily, 
the PANI- $f$-BT nanoparticles reveal a homogeneous dispersion in PEN matrix without agglomeration (Figure $4 \mathrm{~b}$ ). This result is mainly caused by that the PANI layer on PANI- $f$-BT nanoparticles which improves compatibility with PEN. Therefore, the modification of BT with PANI can effectively improve the compatibility between BT and PEN [36].
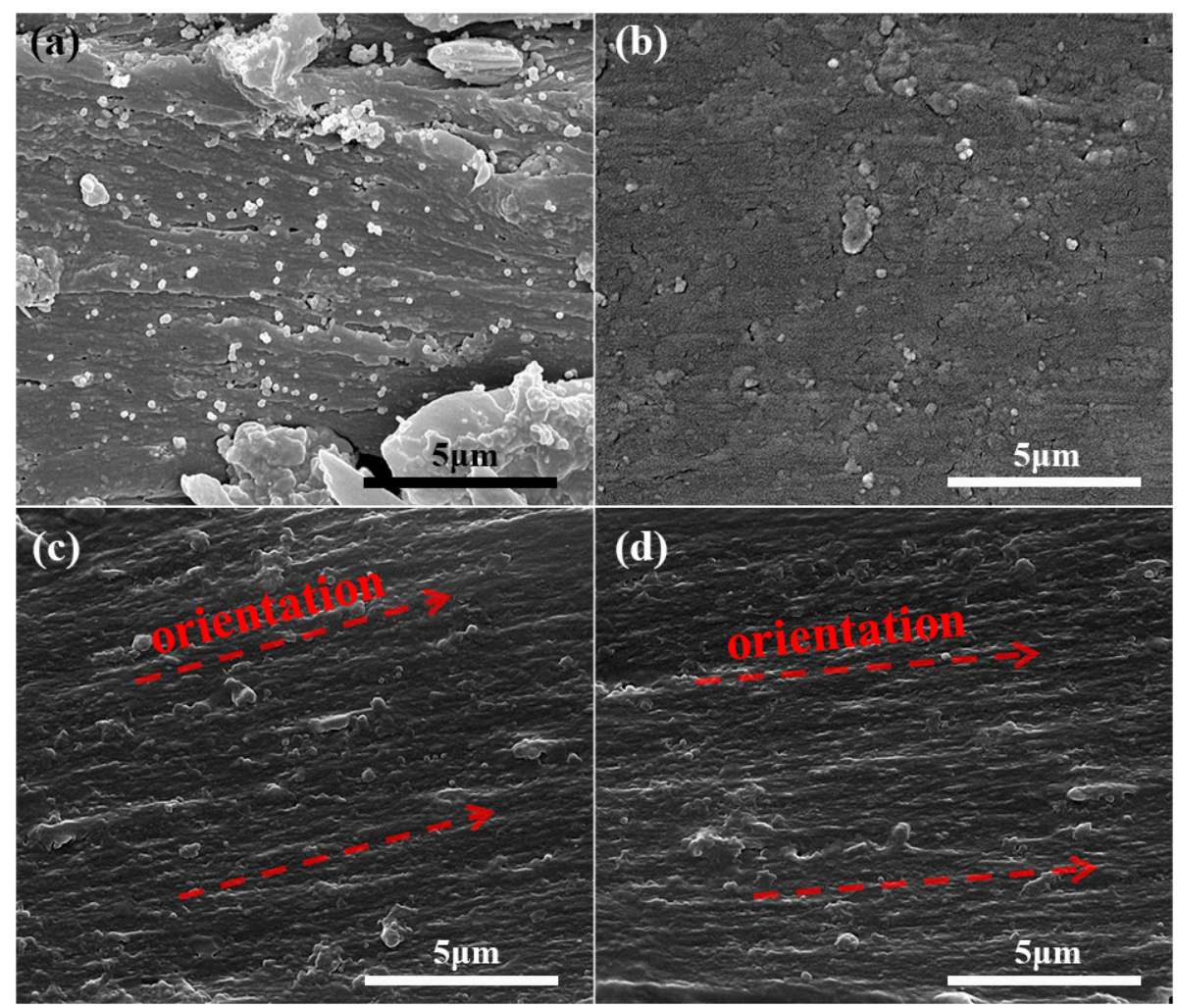

Figure 4. Cross-sectional scanning electron microscopy (SEM) images of (a) PEN/BT; (b) PEN/PANI-f-BT-b;

(c) PEN/PANI-f-BT-b hot-stretched by $50 \%$; (d) PEN/PANI-f-BT-b hot-stretched by $100 \%$.

To achieve the secondary dispersion of PANI- $f$-BT in PEN, the PEN/PANI- $f$-BT composites are hot-stretched in a home-made oven. Figure $4 c$, d are the cross-sectional SEM images of PEN/PANI- $f$-BT-b after hot-stretching at a stretching ratio of $50 \%$ and $100 \%$, from which obvious orientation of the sample caused by the directional arrangement of polymer molecular chains under the action of external forces is observed. After hot-stretching, the PANI- $f$-BT nanoparticles are secondarily dispersed in the PEN matrix along the orientation direction. A schematic model of the evolution process of PANI- $f$-BT in the polymer matrix during uniaxial stretching is presented in Figure 5. Before the hot-stretching, the spherical PANI- $f$-BT is isotropically dispersed in the PEN matrix. With the commencement of the hot-stretching, the PANI- $f$-BT nanoparticles rearrange along the orientation direction of the stretching. Finally, the enhanced dispersion of PANI- $f$-BT in PEN matrix is obtained after the hot-stretching. Combining the improved compatibility between PANI- $f$-BT and PEN and the secondarily dispersion of PANI- $f$-BT in PEN matrix induced by hot-stretching, enhanced properties of the PEN/PANI- $f$-BT composites can be imaged. 

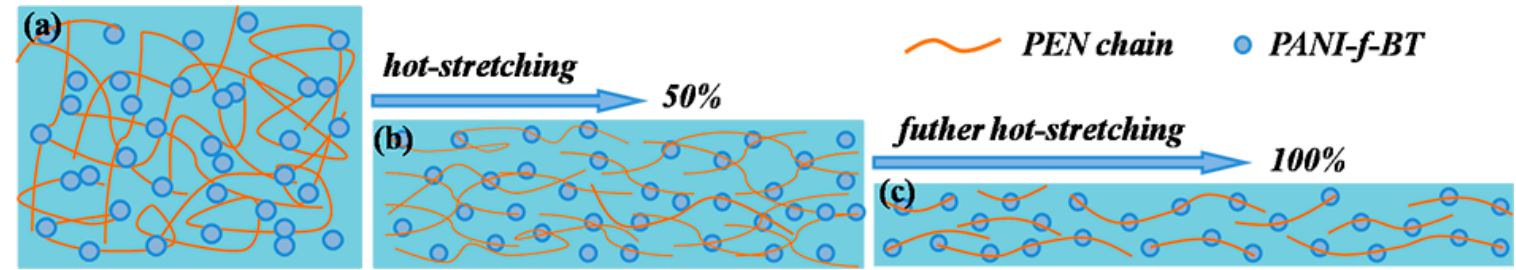

Figure 5. The theoretical model of the evolution process of inner network during uniaxial stretching: (a) the original composite film, the composite film hot-stretched by (b) $50 \%$ and (c) $100 \%$.

\subsection{Thermal Properties and Crystallization of PEN/PANI-f-BT Composites}

As a crystalline polymer, the crystallization behavior of PEN is another important factor affecting the properties of the nanocomposites. The crystallization behavior of PEN/PANI- $f$-BT composites is studied by DSC and XRD. Figure 6 shows the DSC curves of the PEN/BT (Figure 6a) and PEN/PANI- $f$-BT (Figure $6 \mathrm{~b}-\mathrm{d}$ ) nanocomposites before and after hot-stretching. It clearly shows that the melting peaks of all nanocomposites are not observed before hot-stretching, while they appear after hot-stretching. The melting enthalpy $\left(\Delta H_{\mathrm{m}}\right)$ of PEN/PANI- $f$-BT-b at the stretching ratios of $0 \%, 50 \%$ and $100 \%$ is 0 , 6.4 and $9.1 \mathrm{~J} / \mathrm{g}$, respectively (Table 1). With the increase of stretching ratios from $50 \%$ to $100 \%$, the $\Delta H_{\mathrm{m}}$ of these composites increases gradually, meaning that the crystallinity of the nanocomposites increases [25,37]. This would be due to the rearrangement of PEN molecular chains during the hot-stretching resulting the transitions of the samples from amorphous regions to crystalline regions and from irregular crystals to regular crystals [28]. Besides, the half peak width of the melting peaks also shows the crystalline information of the samples. Generally, the perfect crystals exhibit smaller half peak width than the imperfect crystals. The half peak width is $9.34,6.55,5.68$ and $5.71{ }^{\circ} \mathrm{C}$ for PEN/BT, PEN/PANI- $f$-BT-a, PEN/PANI- $f$-BT-b and PEN/PANI- $f$-BT-c respectively, at the stretching ratio of $100 \%$. The widest half peak width of PEN/BT at $100 \%$ stretching ratio is mainly owing to the worst compatibility and dispersion of BT in the PEN matrix as confirmed by the SEM observation (Figure 4a). In addition, DSC curves also demonstrate that the glass transition $\left(T_{\mathrm{g}}\right)$ of the all nanocomposites increases slightly during the hot-stretching process. For instance, the $T_{\mathrm{g}}$ of PEN/PANI-f-BT-b increases from $218.6{ }^{\circ} \mathrm{C}$ to $221.7^{\circ} \mathrm{C}$ as stretching ratios increases from $0 \%$ to $100 \%$ (Figure $6 \mathrm{c}$ and Table 1). This result can also be explained by the arrangement of the PEN chains after hot-stretching, leading to the harder movement of them. Moreover, the increase of crystallinity further limits the movement of the chain segments [38]. Furthermore, the DSC curves for both cooling and heating are shown in Figure S1, as can be seen from the figure that during the first cooling scan and the second heating scan, the $T_{\mathrm{g}} \mathrm{s}$ obtained from the curves are lower than the one obtained from the first heating scan due to the supercooling effect [39]. What is more, the melting point disappears during the first cooling scan and the second heating scan due to the semi-crystalline property of the polymers and slow crystalline rate of the polymers [40]. In addition, we also characterize the crystal structure state of the samples after treatment at $200{ }^{\circ} \mathrm{C}$, which is shown in Figure S2. It can be clearly seen from the figure that the PEN/PANI-f-BT-b nanocomposites with a $50 \%$ and $100 \%$ stretching ratio still show an obvious melting peak in the second heating curve after treating them at $200{ }^{\circ} \mathrm{C}$ for $10 \mathrm{~min}$. It is indicated that the crystal structure of the PEN/PANI- $f$-BT-b nanocomposites is thermodynamic stable when used at $200{ }^{\circ} \mathrm{C}$. More importantly, as shown in Figure S2d, it is clear that the melting peak is also maintained in the second heating curve of the PEN/PANI- $f$-BT-b nanocomposites with a $100 \%$ stretching ratio after treating at $300{ }^{\circ} \mathrm{C}$ for $10 \mathrm{~min}$. Therefore, all these results confirm that the crystal structure of the hot-stretched PEN/PANI- $f$-BT nanocomposite films can still maintain good thermal stability during the practical application $\left(<200^{\circ} \mathrm{C}\right)$. 
Table 1. Thermal and mechanical properties of nanocomposites at different stretching ratios.

\begin{tabular}{|c|c|c|c|c|}
\hline Samples & $T_{\mathrm{g}}\left({ }^{\circ} \mathrm{C}\right)$ & $\Delta H_{\mathrm{m}}(\mathrm{J} / \mathrm{g})$ & Tensile Strength (MPa) & Tensile Modulus (GPa) \\
\hline $\begin{array}{c}\text { PEN/BT } 0 \% \\
0 \%\end{array}$ & 218.8 & - & $67.2 \pm 3.9$ & $1.93 \pm 0.10$ \\
\hline PEN/BT 50\% & 219.5 & 4.2 & $90.3 \pm 5.7$ & $2.25 \pm 0.11$ \\
\hline PEN/BT 100\% & 221.9 & 7.5 & $119.7 \pm 6.3$ & $2.75 \pm 0.15$ \\
\hline $\begin{array}{c}\text { PEN/PANI-f-BT-a } 0 \% \\
0 \%\end{array}$ & 218.5 & - & $78.5 \pm 3.8$ & $1.99 \pm 0.09$ \\
\hline PEN/PANI- $f$-BT-a 50\% & 219.4 & 5.9 & $108.6 \pm 4.2$ & $2.41 \pm 0.13$ \\
\hline PEN/PANI-f-BT-a 100\% & 221.7 & 8.4 & $141.2 \pm 5.9$ & $2.94 \pm 0.12$ \\
\hline $\begin{array}{c}\text { PEN/PANI-f-BT-b 0\% } \\
0 \%\end{array}$ & 218.6 & - & $83.8 \pm 3.6$ & $2.11 \pm 0.08$ \\
\hline PEN/PANI- $f$-BT-b 50\% & 219.4 & 6.4 & $126.4 \pm 4.6$ & $2.77 \pm 0.10$ \\
\hline PEN/PANI- $f$-BT-b 100\% & 221.7 & 9.1 & $161.1 \pm 5.3$ & $3.37 \pm 0.14$ \\
\hline $\begin{array}{c}\text { PEN/PANI- } f-B T-c 0 \% \\
0 \%\end{array}$ & 218.1 & - & $79.6 \pm 3.9$ & $2.01 \pm 0.10$ \\
\hline $\begin{array}{c}\text { PEN/PANI- } f \text {-BT-c } 50 \% \\
50 \%\end{array}$ & 219.0 & 4.7 & $109.1 \pm 5.1$ & $2.57 \pm 0.11$ \\
\hline $\begin{array}{c}\text { PEN/PANI- } f \text {-BT-c } 100 \% \\
100 \%\end{array}$ & 221.4 & 7.6 & $144.3 \pm 5.7$ & $3.05 \pm 0.13$ \\
\hline
\end{tabular}
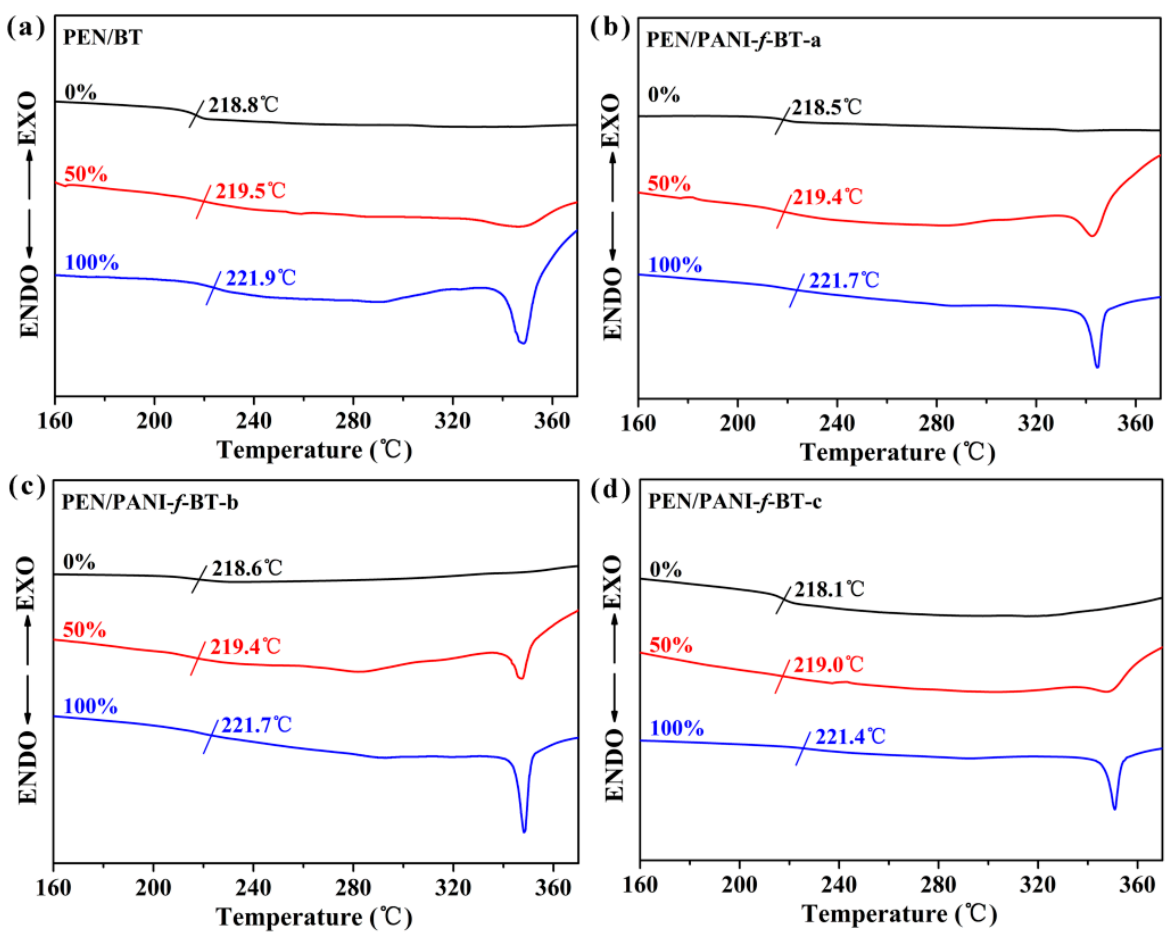

Figure 6. The differential scanning calorimetry (DSC) curves of nanocomposites with different stretching ratios: (a) PEN/BT; (b) PEN/PANI-f-BT-a; (c) PEN/PANI-f-BT-b; (d) PEN/PANI- $f$-BT-c.

XRD is usually employed to study the crystals and crystallinity of samples. Figure 7 typically shows the XRD patterns of PEN/PANI- $f$-BT-b at different stretching ratios. As shown in the figure, the diffraction peaks at around $32^{\circ}, 38^{\circ}$ and $45^{\circ}$ are observed from all three samples which are coming from the diffractions of (110), (111) and (200) of BT. As for PEN, no crystalline peak is observed before hot-stretching. In comparison, two diffraction peaks at $17^{\circ}$ and $23^{\circ}$ which are coming from the diffractions of (111) and (112) of PEN are observed after the hot-stretching. The crystallinities of PEN/PANI- $f$-BT-b with the stretching ratios from $0 \%$ to $100 \%$ are $0 \%, 11.2 \%$ and $16.4 \%$, which are calculated from wide-angle XRD spectrogram by using Jade 6 software [41]. 


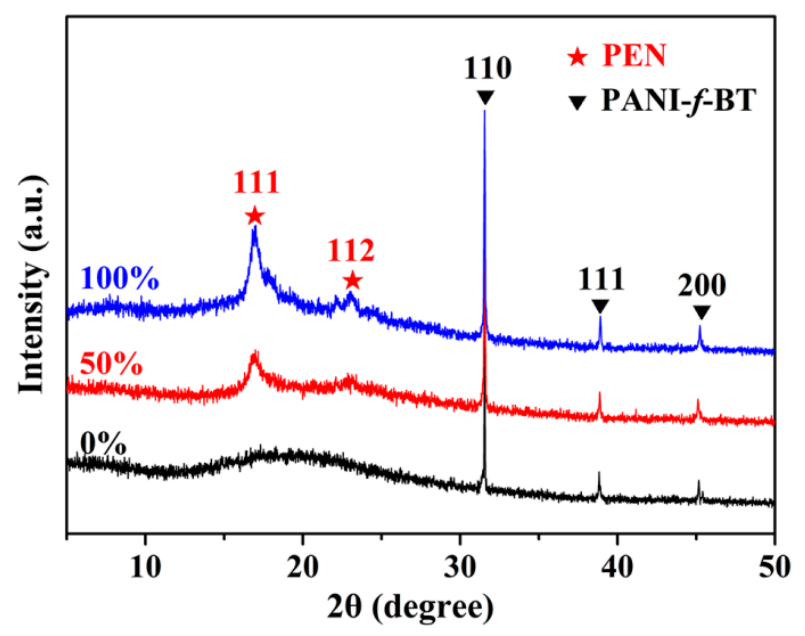

Figure 7. The wide-angle XRD patterns of PEN/PANI- $f$-BT-b at different stretching ratios.

\subsection{Mechanical Properties of PEN/PANI-f-BT Composites}

Resulting from the improved compatibility and crystalline of the composite, their enhanced properties are further investigated. Tensile strength and tensile modulus, two most important mechanical properties of the high-performance engineering plastics, are typically studied. The tensile properties of the PEN-based nanocomposites at different stretching ratios are shown in Figure 8. The tensile strength of PEN/BT nanocomposites is $67.2,90.3$ and $119.7 \mathrm{MPa}$, at the stretching ratio $0 \%, 50 \%$ and $100 \%$, respectively. As expected, the tensile strengths of all nanocomposites demonstrate a significant increase after modifying the surface of BT and hot-stretching, which are shown in Figure 8a. Moreover, tensile strength of PEN/PANI-f-BT-b nanocomposite is $83.8 \mathrm{MPa}$ without stretching. What is more, it increases to $161.1 \mathrm{MPa}$ when the stretching ratio is $100 \%$, with an increment of $90 \%$. The detailed mechanical data of the nanocomposites are listed in Table 1. It is obvious that the tensile strengths of PEN/PANI- $f$-BT nanocomposites are higher than that of PEN/BT nanocomposites, which are attributed to the better dispersion and compatibility between PEN and PANI- $f$-BT. In addition, it can be concluded that a substantial increase in mechanical property of the nanocomposites is contributed by the high orientation of the molecular chains and the newly formed oriented crystals after hot-stretching process $[25,41]$. The tensile modulus of the nanocomposites exhibits a similar tendency as that of tensile strength, which results from the same reasons as mentioned above [25].
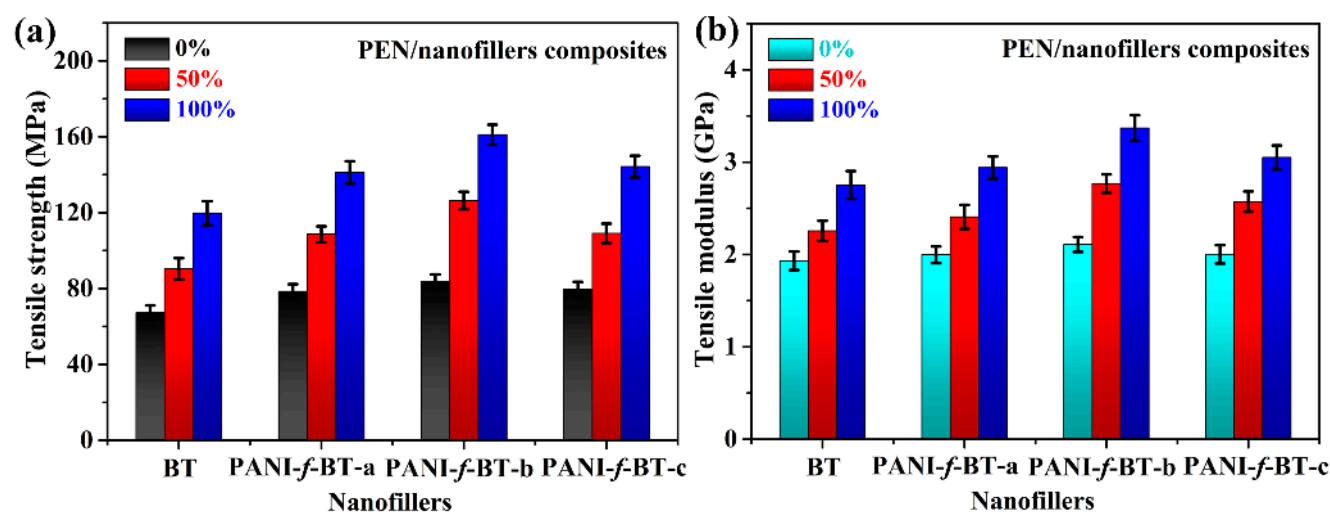

Figure 8. The mechanical properties of nanocomposite films at different stretching ratios: (a) tensile strength and (b) tensile modulus. 


\subsection{Dielectric Properties of PEN/PANI-f-BT Composites}

PEN has shown prospective application in film capacitors and other electronic devices. However, the permittivity of PEN is relatively low $(\sim 4.0$ at $1 \mathrm{kHz})$ which failed to meet the high permittivity requirement for film capacitors. Herein, PANI- $f$-BT nanoparticles are used as a filler to mix with PEN for preparing PEN/PANI- $f$-BT nanocomposites. The dependence between dielectric properties of the obtained nanocomposites and varying frequency (100 Hz to $1 \mathrm{MHz})$ is shown in Figure 9a. Compared with PEN/BT, the dielectric constants of all PEN/PANI-f-BT nanocomposites are slightly lower than those of PEN/BT. The decreasing of dielectric constant of PEN/PANI- $f$-BT nanocomposites is caused by the PANI layer on the surface of BT nanoparticles which will hinder the charge movements from BT to PEN matrix. This usually leads to a decrease in interfacial polarization of the system [42]. In addition, it is clear that the permittivity of PEN/PANI- $f$-BT nanocomposites is more stable than that of PEN/BT nanocomposite with the change of frequency $(100 \mathrm{~Hz}$ to $1 \mathrm{MHz})$. This is due to that the introduction of organic shell layer which enhances the compatibility between nanofillers and PEN matrix which depresses the Maxwell-Wagner polarization [30]. The dielectric loss of the PEN/PANI- $f$-BT nanocomposites is shown in Figure $9 \mathrm{~b}$. Although the content of nanofillers is up to $40 \mathrm{wt} \%$, the dielectric loss of PEN/PANI- $f$-BT nanocomposites is still below $0.028(1 \mathrm{kHz})$. This phenomenon also resulted from the improved compatibility between PANI- $f$-BT and PEN [30]. What is more, the dielectric loss of the PEN/PANI- $f$-BT nanocomposites demonstrates a similar trend with the changing of frequency and fillers as that of their permittivity. Furthermore, the electrical conductivity of the studied samples is shown in Figure S3. It can be seen from the figure that the electrical conductivity of PEN/PANI- $f$-BT nanocomposites is almost the same $\left(10^{-10} \mathrm{~S} \mathrm{~cm}^{-1}\right)$ at $100 \mathrm{~Hz}$ (Figure S3a), which indicates that all the nanocomposite films are insulators.
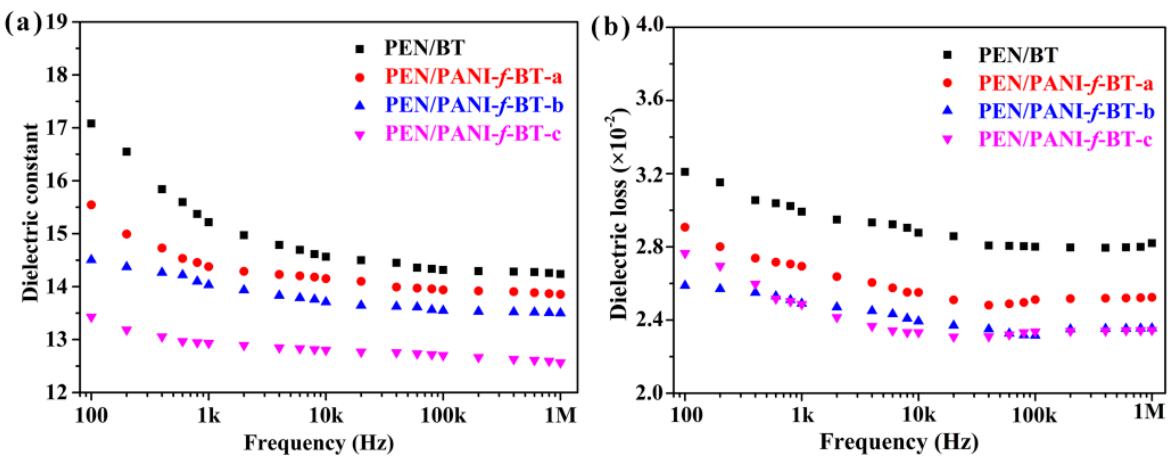

Figure 9. (a) Dielectric constant and (b) dielectric loss of the nanocomposites with the changing of frequency.

Compared with the commonly used biaxially oriented polypropylene (BOPP) and Poly(vinylidene fluoride) (PVDF), PEN, which is a kind of special thermoplastic engineering material, has demonstrated its potential application as high temperature dielectrics. Therefore, the permittivity of all samples at different temperature is further researched. As shown in Figure 10a, the dielectric constant of nanocomposites is measured at $1 \mathrm{kHz}$ in the range of 25 to $250{ }^{\circ} \mathrm{C}$. It is clear that the dielectric constant of all nanocomposites is stable before their $T_{\mathrm{g}}$, and it increases hastily and obviously when the temperature exceeds their $T_{\mathrm{g}}$. This is due to the molecular chains of the PEN that are frozen at a temperature lower than its $T_{\mathrm{g}}$. However, as the temperature increases, the macromolecular chains are thawed which strengthens the mobility of electrons and enhances polarization in the system [43]. As a result, the $T_{\mathrm{g}}$ of the polymeric dielectrics can be obtained from their permittivity-temperature curves. As shown in Figure 10a, the $T_{\mathrm{g}}$ of PEN/PANI-f-BT-c obtained from the permittivity-temperature curve is $218^{\circ} \mathrm{C}$ which is the same as that obtained from its DSC curve. The $T_{\mathrm{g}}$ of the other composites is also around $218^{\circ} \mathrm{C}$. The high $T_{\mathrm{g}}$ of the composites ensures the potential application of them at high temperature. Beside the qualitative description of the stable permittivity of the composites before 
their $T_{\mathrm{g}}$, the quantitative value of dielectric constant with the change of temperature (temperature coefficients of dielectric constant) is calculated according to Equation (1) [44]:

$$
\tau_{\varepsilon}=\frac{\varepsilon_{\mathrm{T} 2}-\varepsilon_{\mathrm{T} 1}}{\varepsilon_{\mathrm{T} 0}\left(T_{2}-T_{1}\right)}
$$

where $\tau_{\varepsilon}$ is the temperature coefficient of dielectric constant, $\varepsilon_{\mathrm{T} 0}$ is the dielectric constant of room temperature, $\varepsilon_{\mathrm{T} 1}$ is the dielectric constant of initial temperature and $\varepsilon_{\mathrm{T} 2}$ is the dielectric constant of the final temperature. $T_{1}$ and $T_{2}$ are the initial and final temperatures, respectively. According to Equation (1), the calculated results of the temperature coefficients of dielectric constant of all nanocomposites are shown in Figure 10b. The temperature coefficients of dielectric constant of the composites are lower than $5 \times 10^{-4}{ }^{\circ} \mathrm{C}^{-1}$ within the temperature range from 25 to $100{ }^{\circ} \mathrm{C}$. They are still lower than $3 \times 10^{-3}{ }^{\circ} \mathrm{C}^{-1}$ even though in the temperature range from 25 to $200^{\circ} \mathrm{C}$, indicating that they are extraordinarily stable, even at temperature up to $200^{\circ} \mathrm{C}$. In addition, it is notable that the temperature coefficients of dielectric constant of the composites decrease with the increase of the PANI content in the PANI- $f$-BT. This result is also largely due to the introduction of organic shell layer can improve the compatibility between nanoparticles and PEN matrix, which can effectively reduce the charge accumulation and interfacial polarization between inorganic nanoparticles and matrix [30].
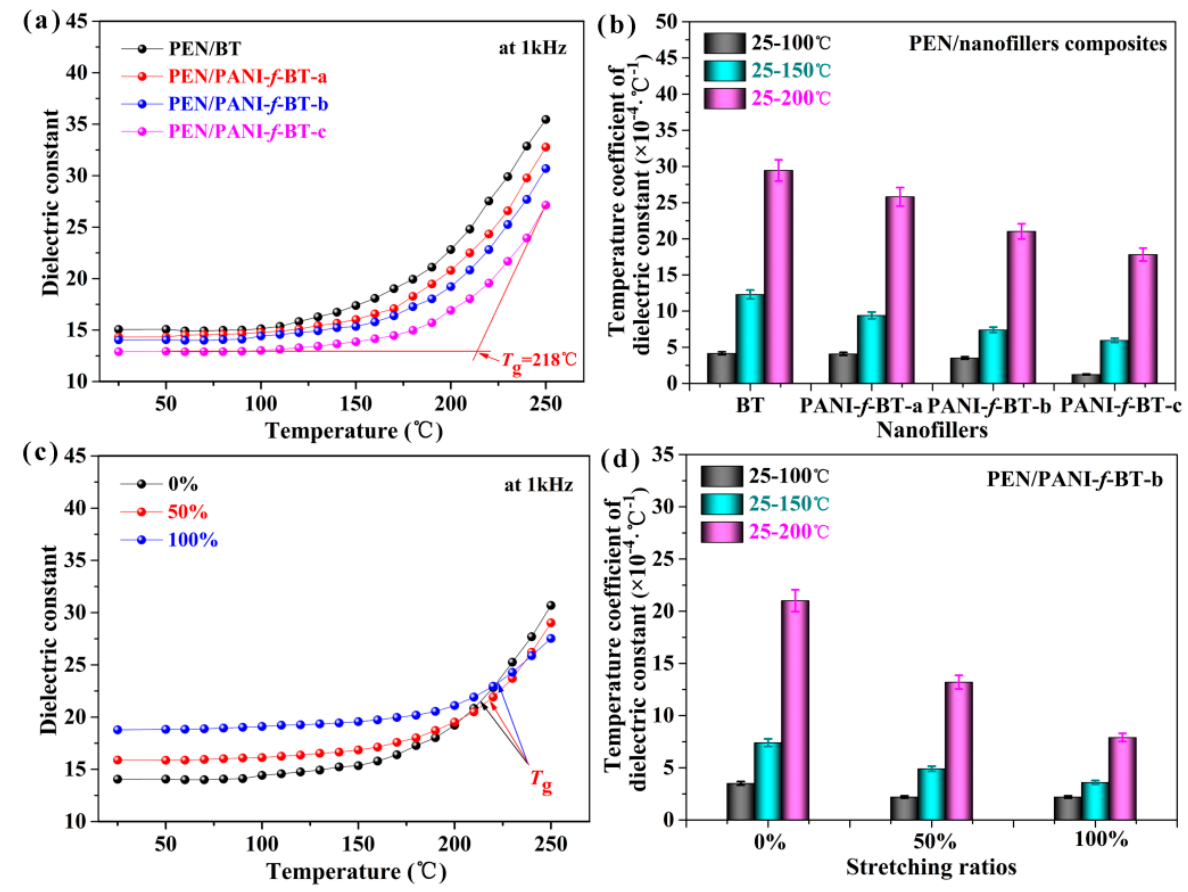

Figure 10. (a) Permittivity-temperature dependences and (b) temperature coefficients of dielectric constant of the nanocomposites; (c) permittivity-temperature dependences and (d) temperature coefficients of dielectric constant of PEN/PANI- $f$-BT-b at different stretching ratios.

Moreover, to make a clear view of the properties of the PEN/PANI-f-BT nanocomposites, a comparison of dielectric constant, dielectric loss and working temperature at room temperature and $1 \mathrm{kHz}$ of reported polymer-based composites are summarized in Table 2. As can be seen from the table, the dielectric constant and loss of PEN/PANI-f-BT are 14 and 0.025 when the content of PANI- $f$-BT nanoparticles is $40 \mathrm{wt} \%$. Although the dielectric constant is lower than that of the most widely used PVDF based composites, it is comparable to the P(VDF-HFP)/BT-OPA, PES/BT-CuPc and PAEN/BT@CPAEN system. In addition, the dielectric loss of PEN/PANI- $f$-BT nanocomposites maintains at a relatively low level and is lower than that of most PVDF based composites. More importantly, the inherent low temperature resistance of $\operatorname{PVDF}\left(<120^{\circ} \mathrm{C}\right)$ will limit its application in high temperature environment. 
In comparison, in this work, the PEN/PANI-f-BT nanocomposites can be used as flexible dielectric films at around $200{ }^{\circ} \mathrm{C}$, which provides a new approach for preparing high-temperature-resistant dielectric films.

Table 2. Dielectric constant at $1 \mathrm{kHz}$ and $25^{\circ} \mathrm{C}$, dielectric loss at $1 \mathrm{kHz}$ and $25^{\circ} \mathrm{C}$, working temperature of typical polymer-based composites.

\begin{tabular}{|c|c|c|c|c|c|}
\hline Samples & Content & $\begin{array}{c}\text { Dielectric Constant } \\
\left(1 \mathrm{kHz}, 25^{\circ} \mathrm{C}\right)\end{array}$ & $\begin{array}{l}\text { Dielectric Loss } \\
\left(1 \mathrm{kHz}, 25^{\circ} \mathrm{C}\right)\end{array}$ & $\begin{array}{c}\text { Working } \\
\text { Temperature }\left({ }^{\circ} \mathrm{C}\right) \\
\end{array}$ & Ref. \\
\hline $\mathrm{PVDF} / \mathrm{BT}$ & $60 \mathrm{vol} \%$ & 95 & $\sim 0.04$ & $<120$ & [45] \\
\hline PVDF/BT-PDOPA & $50 \mathrm{vol} \%$ & 56.8 & 0.04 & $<120$ & [46] \\
\hline PVDF/BT-TDPA & $40 \mathrm{vol} \%$ & 48 & 0.03 & $<120$ & [47] \\
\hline $\mathrm{PVDF} / \mathrm{BT}-\mathrm{SiO}_{2}$ & $10 \mathrm{vol} \%$ & 14.7 & 0.02 & $<120$ & [48] \\
\hline hydantoin/BT-P(VDF-HFP) & $50 \mathrm{vol} \%$ & 48.9 & 0.06 & 120 & [49] \\
\hline P(VDF-HFP)/BT-OPA & $30 \mathrm{vol} \%$ & $\sim 15$ & 0.08 & 120 & [50] \\
\hline PES/BT-CuPc & $40 \mathrm{vol} \%$ & $\sim 17$ & $\sim 0.12$ & $\sim 160$ & [51] \\
\hline PAEN/BT@CPAEN & $40 w t \%$ & 13 & 0.023 & $\sim 180$ & [30] \\
\hline PEN/PANI- $f$-BT & $40 \mathrm{wt} \%$ & 14 & 0.025 & $\sim 200$ & This work \\
\hline
\end{tabular}

The dielectric properties of the PEN/PANI-f-BT nanocomposites are further improved by hot-stretching. As shown in Figure 10c, the dielectric constant of PEN/PANI- $f$-BT-b is 14.0 at $1 \mathrm{kHz}$ without stretching $\left(\right.$ at $\left.25^{\circ} \mathrm{C}\right)$. After hot-stretching, its dielectric constant increases to 15.9 and 18.7 when the stretching ratio is $50 \%$ and $100 \%$ respectively $\left(\right.$ at $25^{\circ} \mathrm{C}$ ). It is well-known that the micro-capacitor networks are often formed in the nanocomposites [28]. During hot-stretching, the disordered nanoparticles are realigned to form the oriented micro-capacitors in the polymer matrix along the orientation direction (Figure 5), contributing to the enhancement of the dielectric constant of nanocomposites. In addition, the electrical conductivity of PEN/PANI- $f$-BT-b nanocomposites presents a slight increase with the increase of stretching ratio (Figure S3b). This is a result of the second dispersion of PANI- $f$-BT-b in the system. What is more, the permittivity of the PEN/PANI- $f$-BT-b nanocomposites after hot-stretching at different temperatures is also investigated in this work, as shown in Figure 10c. It can be seen that the $T_{\mathrm{g}}$ of PEN/PANI- $f$-BT-b obtained from the permittivity-temperature curve increases to $219^{\circ} \mathrm{C}$ and $221^{\circ} \mathrm{C}$ at the $50 \%$ and $100 \%$ respectively, indicating that the composites can be used at higher temperature after hot-stretching. It is well-known that the service temperature of BOPP is higher than PP due to the stretching of the sample. Furthermore, the temperature coefficients of dielectric constant of PEN/PANI- $f$-BT-b nanocomposites at different stretching ratios are shown in Figure 10d. As can be seen, the temperature coefficients of dielectric constant of PEN/PANI-f-BT-b nanocomposites exhibit a gradual downward trend. More importantly, the temperature coefficients of dielectric constant of PEN/PANI- $f$-BT-b are lower than $5 \times 10^{-4}{ }^{\circ} \mathrm{C}$, which are very important for its application at high temperature. This is because the high orientation of the molecular chain and the increase of crystallinity limit the movement of the chain segments, which is consistent with the conclusion of the thermal properties [52]. The results reveal that the modification of the filler and hot-stretching method can effectively increase the dielectric constant and the stability of the nanocomposites at different temperatures, which presents great potential for it to be used as a high performance dielectric film in harsh environments.

\section{Conclusions}

In conclusion, enhanced dielectric and mechanical properties of polyarylene ether nitrile are obtained through secondary dispersion of polyaniline functionalized barium titanate (PANI- $f$-BT) by hot-stretching. PANI- $f$-BT nanoparticles with different PANI contents are prepared via in-situ aniline polymerization technology, and then characterized by TEM, XPS, FTIR and TGA. The results confirm that the polymer layers have uniformly enclosed on the surface of $\mathrm{BaTiO}_{3}$ nanoparticles. The obtained PANI- $f$-BT nanoparticles are used as functional fillers to compound with PEN for preparing the PEN/PANI- $f$-BT nanocomposites. In addition, these PEN-based nanocomposites are uniaxial hot-stretched by $50 \%$ and $100 \%$ at $280{ }^{\circ} \mathrm{C}$ to obtain the oriented nanocomposite films. The results show 
that the PANI- $f$-BT nanoparticles present well compatibility and dispersion in the PEN matrix, and the hot-stretching can achieve a second dispersion of the PANI- $f$-BT nanoparticles in PEN, which can effectively enhance the comprehensive properties of nanocomposites like mechanical properties, crystallinity, dielectric constant and so on. When the stretching ratios increase from $0 \%$ to $100 \%$, the tensile strengths of PEN/PANI- $f$-BT-b nanocomposite film increase from 83.8 to $161.1 \mathrm{MPa}$, and the crystallinities increase from $0 \%$ to $16.4 \%$. Most importantly, the permittivity temperature dependences of nanocomposites after hot-stretching are more stable than that of original nanocomposites. The excellent performances of the stretched composites indicate that these samples present a great potential to be used as a high-performance dielectric film in high-temperature environments.

Supplementary Materials: The following are available online at http://www.mdpi.com/2079-4991/9/7/1006/s1, Figure S1: The DSC curves of PEN/PANI-f-BT nanocomposite films with different stretching ratios. Figure S2: The DSC curves of PEN/PANI-f-BT-b nanocomposite films with different stretching ratios. Figure S3: The electrical conductivity of PEN/PANI- $f$-BT nanocomposites.

Author Contributions: Y.Y. and X.L. conceived and designed the experiments; Y.Y. performed the experiments; L.T. (Ling Tu), Y.W. and L.T. (Lifen Tong) analyzed the data; Y.Y. wrote the paper. R.W. and X.L. edited and revised manuscript. All the authors approved the final version of the manuscript.

Funding: This research received no external funding.

Acknowledgments: The authors wish to give thanks for the financial supports from the National Natural Science Foundation of China (No. 51773028 and 51603029), China Postdoctoral Science Foundation (2017M623001) and National Postdoctoral Program for Innovative Talents (BX201700044).

Conflicts of Interest: The authors declare no conflict of interest.

\section{References}

1. Dang, Z.M.; Yuan, J.K.; Yao, S.H.; Liao, R.J. Flexible nanodielectric materials with high permittivity for power energy storage. Adv. Mater. 2013, 25, 6334-6365. [CrossRef]

2. Chu, B.J.; Zhou, X.; Ren, K.L.; Neese, B.; Lin, M.R.; Wang, Q.; Bauer, F.; Zhang, Q.M. A dielectric polymer with high electric energy density and fast discharge speed. Science 2006, 313, 334-336. [CrossRef] [PubMed]

3. Hao, Y.N.; Wang, X.H.; O'Brien, S.; Lombardi, J.; Li, L.T. Flexible $\mathrm{BaTiO}_{3} / \mathrm{PVDF}$ gradated multilayer nanocomposite film with enhanced dielectric strength and high energy density. J. Mater. Chem. C 2015, 3, 9740-9747. [CrossRef]

4. Kim, P.; Jones, S.C.; Hotchkiss, P.J.; Haddock, J.N.; Kippelen, B.; Marder, S.R.; Perry, J.W. Phosphonic acidmodified barium titanate polymer nanocomposites with high permittivity and dielectric strength. Adv Mater. 2007, 19, 1001-1005. [CrossRef]

5. Maier, G. Low dielectric constant polymers for microelectronics. Prog. Polym. Sci. 2001, 26, 3-65. [CrossRef]

6. Qi, L.; Lee, B.I.; Chen, S.; Samuels, W.D.; Exarhos, G.J. High-dielectric-constant silver-epoxy composites as embedded dielectrics. Adv. Mater. 2005, 17, 1777-1781. [CrossRef]

7. Bi, K.; Bi, M.; Hao, Y.; Luo, W.; Cai, Z.; Wang, X.; Huang, Y. Ultrafine core-shell $\mathrm{BaTiO}_{3} @ \mathrm{SiO}_{2}$ structures for nanocomposite capacitors with high energy density. Nano Energy 2018, 51, 513-523. [CrossRef]

8. Maliakal, A.; Katz, H.; Cotts, P.M.; Subramoney, S.; Mirau, P. Inorganic oxide core, polymer shell nanocomposite as a high- $k$ gate dielectric for flexible electronics applications. J. Am. Chem. Soc. 2005, 127, 14655-14662. [CrossRef]

9. You, Y.; Zhan, C.H.; Tu, L.; Wang, Y.J.; Hu, W.B.; Wei, R.B.; Liu, X.B. Polyarylene ether nitrile-based high- $k$ composites for dielectric applications. Int. J. Polym. Sci. 2018, 5161908. [CrossRef]

10. Zotti, A.; Zuppolini, S.; Borriello, A.; Zarrelli, M. Thermal properties and fracture toughness of epoxy nanocomposites loaded with hyperbranched-polymers-based core/shell nanoparticles. Nanomaterials 2019, 9, 418. [CrossRef]

11. Li, J.; Seok, S.I.; Chu, B.; Dogan, F.; Zhang, Q.; Wang, Q. Nanocomposites of ferroelectric polymers with $\mathrm{TiO}_{2}$ nanoparticles exhibiting significantly enhanced electrical energy density. Adv. Mater. 2009, 21, $217-221$. [CrossRef] 
12. Wang, Y.J.; Tong, L.F.; You, Y.; Tu, L.; Zhou, M.R.; Liu, X.B. Polyethylenimine assisted bio-inspired surface functionalization of hexagonal boron nitride for enhancing the crystallization and the properties of poly(arylene ether nitrile). Nanomaterials 2019, 9, 760. [CrossRef] [PubMed]

13. Wei, R.B.; Wang, J.L.; Zhang, H.X.; Han, W.H.; Liu, X.B. Crosslinked polyarylene ether nitrile interpenetrating with zinc ion bridged graphene sheet and carbon nanotube network. Polymers 2017, 9, 342. [CrossRef] [PubMed]

14. Wang, Z.D.; Liu, J.Y.; Cheng, Y.H.; Chen, S.Y.; Yang, M.M.; Huang, J.L.; Wang, H.K.; Wu, G.L.; Wu, H.J. Alignment of boron nitride nanofibers in epoxy composite films for thermal conductivity and dielectric breakdown strength improvement. Nanomaterials 2018, 8, 242. [CrossRef] [PubMed]

15. Zhi, C.; Bando, Y.; Terao, T.; Tang, C.; Kuwahara, H.; Golberg, D. Boron nanotube-polymer composites: Towards thermoconductive, electrically insulating polymeric composites with boron nitride nanotubes as fillers. Adv. Funct. Mater. 2009, 19, 1857-1862. [CrossRef]

16. Xu, M.Z.; Lei, Y.X.; Ren, D.X.; Chen, S.J.; Chen, L.; Liu, X.B. Synergistic effects of functional CNTs and h-BN on enhanced thermal conductivity of epoxy/cyanate matrix composites. Nanomaterials 2018, 8, 997. [CrossRef] [PubMed]

17. Yang, M.; Hu, C.; Zhao, H.; Haghi-Ashtiani, P.; He, D.; Yang, Y.; Yuan, J.; Bai, J. Core@double-shells nanowires strategy for simultaneously improving dielectric constants and suppressing losses of poly (vinylidene fluoride) nanocomposites. Carbon 2018, 132, 152-156. [CrossRef]

18. Ma, J.; Azhar, U.; Zong, C.; Zhang, Y.; Xu, A.; Zhai, C.; Zhang, L.; Zhang, S. Core-shell structured PVDF@BT nanoparticles for dielectric materials: A novel composite to prove the dependence of dielectric properties on ferroelectric shell. Mater. Design 2019, 164, 107556. [CrossRef]

19. Song, Y.; Shen, Y.; Liu, H.; Lin, Y.; Li, M.; Nan, C.W. Improving the dielectric constants and breakdown strength of polymer composites: Effects of the shape of the $\mathrm{BaTiO}_{3}$ nanoinclusions, surface modification and polymer matrix. J. Mater. Chem. 2012, 22, 16491-16498. [CrossRef]

20. Niu, Y.; Bai, Y.; Yu, K.; Wang, Y.; Xiang, F.; Wang, H. Effect of the modifier structure on the performance of barium titanate/poly(vinylidene fluoride) nanocomposites for energy storage applications. ACS Appl. Mater. Interfaces 2015, 7, 24168-24176. [CrossRef]

21. Wei, R.; Li, K.; Ma, J.; Zhang, H.; Liu, X. Improving dielectric properties of polyarylene ether nitrile with conducting polyaniline. J. Mater. Sci. Mater. Electron. 2016, 27, 9565-9571. [CrossRef]

22. Yu, S.; Qin, F.; Wang, G. Improving the dielectric properties of poly (vinylidene fluoride) composites by using poly (vinyl pyrrolidone)-encapsulated polyaniline nanorods. J. Mater. Chem. C 2016, 4, 1504-1510. [CrossRef]

23. Zhang, X.; He, Q.L.; Gu, H.B.; Wei, S.Y.; Guo, Z.H. Polyaniline stabilized barium titanate nanoparticles reinforced epoxy nanocomposites with high dielectric permittivity and reduced flammability. J. Mater. Chem. C 2013, 1, 2886-2899. [CrossRef]

24. Li, Z.M.; Yang, M.B.; Lu, A.; Feng, J.M.; Huang, R. Tensile properties of poly(ethylene terephthalate) and polyethylene in-situ microfiber reinforced composite formed via slit die extrusion and hot-stretching. Mater. Lett. 2002, 56, 756-762. [CrossRef]

25. You, Y.; Huang, X.; Pu, Z.; Jia, K.; Liu, X. Enhanced crystallinity, mechanical and dielectric properties of biphenyl polyarylene ether nitriles by unidirectional hot-stretching. J. Polym. Res. 2015, 22, 221. [CrossRef]

26. Li, L.; Zhou, T.; Liu, J.Z.; Ran, Q.P.; Ye, G.D.; Zhang, J.H.; Liu, P.Q.; Zhang, A.; Yang, Z.Q.; Xu, D.G.; et al. Formation of a large-scale shish-kebab structure of polyoxymethylene in the melt spinning and the crystalline morphology evolution after hot stretching. Polym. Adv. Technol. 2015, 26, 77-84. [CrossRef]

27. Tian, Y.; Zhu, C.Z.; Gong, J.H.; Yang, S.L.; Ma, J.H.; Xu, J. Lamellae break induced formation of shish-kebab during hot stretching of ultra-high molecular weight polyethylene precursor fibers investigated by in situ small angle $X$-ray scattering. Polymer 2014, 55, 4299-4306. [CrossRef]

28. You, Y.; Du, X.; Mao, H.; Tang, X.; Wei, R.; Liu, X. Synergistic enhancement of mechanical, crystalline and dielectric properties of polyarylene ether nitrile-based nanocomposites by unidirectional hot stretching-quenching. Polym. Int. 2017, 66, 1151-1158. [CrossRef]

29. Tian, C.; Du, Y.; Xu, P.; Qiang, R.; Wang, Y.; Ding, D.; Xue, J.; Ma, J.; Zhao, H.; Han, X. Constructing uniform core-shell PPy@PANI composites with tunable shell thickness toward enhancement in microwave absorption. ACS Appl. Mater. Interfaces 2015, 7, 20090-20099. [CrossRef] 
30. Tang, H.L.; Wang, P.; Zheng, P.L.; Liu, X.B. Core-shell structured BaTiO3 @polymer hybrid nanofiller for poly(arylene ether nitrile) nanocomposites with enhanced dielectric properties and high thermal stability. Compos. Sci. Technol. 2016, 123, 134-142. [CrossRef]

31. Kim, J.; Kim, D.; Kim, J.; Kim, Y.; Hui, K.N.; Lee, H. Selective substitution and tetragonality by co-doping of dysprosium and thulium on dielectric properties of barium titanate ceramics. Electron. Mater. Lett. 2011, 7, 155-159. [CrossRef]

32. Li, Y.; Li, J.; Gao, X.; Qi, S.; Ma, J.; Zhu, J. Synthesis of stabilized dispersion covalently-jointed SiO ${ }_{2} @$ polyaniline with core-shell structure and anticorrosion performance of its hydrophobic coating for Mg-Li alloy. Appl. Surf. Sci. 2018, 462, 362-372. [CrossRef]

33. You, Y.; Wang, Y.; Tu, L.; Tong, L.; Wei, R.; Liu, X. Interface modulation of core-shell structured $\mathrm{BaTiO}_{3} @$ polyaniline for novel dielectric materials from its nanocomposite with polyarylene ether nitrile. Polymers 2018, 10, 1378. [CrossRef] [PubMed]

34. Yang, Y.; Wang, X.H.; Sun, C.K.; Li, L.T. Structure study of single crystal $\mathrm{BaTiO}_{3}$ nanotube arrays produced by the hydrothermal method. Nanotechnology 2009, 20, 055709. [CrossRef] [PubMed]

35. Qaiser, A.A.; Hyland, M.M.; Patterson, D.A. Surface and charge transport characterization of polyanilinecellulose acetate composite membranes. J. Phys. Chem. B 2011, 115, 1652-1661. [CrossRef] [PubMed]

36. Wei, R.; Yang, R.; Xiong, Z.; Xiao, Q.; Li, K.; Liu, X. Enhanced dielectric properties of polyarylene ether nitriles filled with core-shell structured $\mathrm{PbZrO}_{3}$ around $\mathrm{BaTiO}_{3}$ nanoparticles. J. Electron. Mater. 2018, 47, 6177-6184. [CrossRef]

37. You, Y.; Wei, R.; Yang, R.; Yang, W.; Hua, X.; Liu, X. Crystallization behaviors of polyarylene ether nitrile filled in multi-walled carbon nanotubes. RSC Adv. 2016, 6, 70877-70883. [CrossRef]

38. Tu, L.; You, Y.; Tong, L.; Wang, Y.; Hu, W.; Wei, R.; Liu, X. Crystallinity of poly(arylene ether nitrile) copolymers containing hydroquinone and bisphenol A segments. J. Appl. Polym. Sci. 2018, 135, 46412. [CrossRef]

39. Mollova, A.; Androsch, R.; Mileva, D.; Schick, C.; Benhamida, A. Effect of supercooling on crystallization of polyamide 11. Macromolecules 2013, 46, 828-835. [CrossRef]

40. Mao, M.; Das, S.; Turner, S.R. Synthesis and characterization of poly(aryl ether sulfone) copolymers containing terphenyl groups in the backbone. Polymer 2007, 48, 6241-6245. [CrossRef]

41. Wei, R.; Tu, L.; You, Y.; Zhan, C.; Wang, Y.; Liu, X. Fabrication of crosslinked single-component polyarylene ether nitrile composite with enhanced dielectric properties. Polymer 2019, 161, 162-169. [CrossRef]

42. Huang, X.; Jiang, P. Core-shell structured high- $k$ polymer nanocomposites for energy storage and dielectric applications. Adv. Mater. 2014, 27, 546-554. [CrossRef] [PubMed]

43. Li, W.; Elzatahry, A.; Aldhayan, D.; Zhao, D.Y. Core-shell structured titanium dioxide nanomaterials for solar energy utilization. Chem. Soc. Rev. 2018, 47, 8203-8237. [CrossRef] [PubMed]

44. Yang, R.; Wei, R.; Tong, L.; Jia, K.; Liu, X.; Li, K. Crosslinked polyarylene ether nitrile film as flexible dielectric materials with ultrahigh thermal stability. Sci. Rep. 2016, 6, 36434. [CrossRef] [PubMed]

45. Prateek; Thakur, V.K.; Gupta, R.K. Recent progress on ferroelectric polymer-based nanocomposites for high energy density capacitors: Synthesis, dielectric properties, and future aspects. Chem. Rev. 2016, 116, 4260-4317. [CrossRef] [PubMed]

46. Lin, M.F.; Thakur, V.K.; Tan, E.J.; Lee, P.S. Surface functionalization of $\mathrm{BaTiO}_{3}$ nanoparticles and improved electrical properties of $\mathrm{BaTiO}_{3} /$ polyvinylidene fluoride composite. RSC Adv. 2011, 1, 576-578. [CrossRef]

47. Ye,H.J.; Shao, W.Z.; Zhen, L. Tetradecylphosphonic acid modified $\mathrm{BaTiO}_{3}$ nanoparticles and its nanocomposite. Colloids Surf. A 2013, 427, 19-25. [CrossRef]

48. Yu, K.; Niu, Y.; Bai, Y.; Zhou, Y.; Wang, H. Poly(vinylidene fluoride) polymer based nanocomposites with significantly reduced energy loss by filling with core-shell structured $\mathrm{BaTiO}_{3} / \mathrm{SiO}_{2}$ nanoparticles. Appl. Phys. Lett. 2013, 102, 102903. [CrossRef]

49. Luo, H.; Zhang, D.; Jiang, C.; Yuan, X.; Chen, C.; Zhou, K.C. Improved dielectric properties and energy storage density of poly(vinylidene fluoride-co-hexafluoropropylene) nanocomposite with hydantoin epoxy resin coated $\mathrm{BaTiO}_{3}$. ACS Appl. Mater. Interfaces 2015, 7, 8061-8069. [CrossRef] [PubMed]

50. Ehrhardt, C.; Fettkenhauer, C.; Glenneberg, J.; Münchgesang, W.; Pientschke, C.; Großmann, T.; Zenkner, M.; Wagner, G.; Leipner, H.S.; Buchsteiner, A.; et al. $\mathrm{BaTiO}_{3}-\mathrm{P}(\mathrm{VDF}-\mathrm{HFP})$ nanocomposite dielectrics-influence of surface modification and dispersion additives. Mater. Sci. Eng. B 2013, 178, 881-888. [CrossRef] 
51. Xu, W.H.; Yang, G.; Jin, L.; Liu, J.; Zhang, Y.H.; Zhang, Z.C.; Jiang, Z.H. High- $k$ polymer nanocomposites filled with hyperbranched phthalocyanine-coated $\mathrm{BaTiO}_{3}$ for high-temperature and elevated field applications. ACS Appl. Mater. Interfaces 2018, 10, 11233-11241. [CrossRef] [PubMed]

52. Song, Z.Y.; Hou, X.X.; Zhang, L.Q.; Wu, S.Z. Enhancing crystallinity and orientation by hot-stretching to improve the mechanical properties of electrospun partially aligned polyacrylonitrile (PAN) nanocomposites. Materials 2011, 4, 621-632. [CrossRef] [PubMed]

C 2019 by the authors. Licensee MDPI, Basel, Switzerland. This article is an open access article distributed under the terms and conditions of the Creative Commons Attribution (CC BY) license (http://creativecommons.org/licenses/by/4.0/). 